\title{
Structural and functional neuroimaging of late-life depression: a coordinate- based meta-analysis
}

\author{
Amin Saberi, MD ${ }^{1}$; Esmaeil Mohammadi, MD ${ }^{1,2}$; Mojtaba Zarei, MD, PhD ${ }^{1}$; Simon B. Eickhoff, \\ $\mathrm{MD}^{3,4}$; Masoud Tahmasian, $\mathrm{MD}, \mathrm{PhD}^{1}$.
}

\begin{abstract}
${ }^{1}$ Institute of Medical Science and Technology, Shahid Beheshti University, Tehran, Iran
${ }^{2}$ Non-Communicable Diseases Research Center, Endocrinology and Metabolism Population Sciences Institute, Tehran University of Medical Sciences, Tehran, Iran

3Institute of Neuroscience and Medicine (INM-7: Brain and Behaviour), Research Centre Jülich, Jülich, Germany

4Institute of Systems Neuroscience, Heinrich Heine University Düsseldorf, Düsseldorf, Germany
\end{abstract}

\section{Corresponding Author}

Dr. Masoud Tahmasian, Institute of Medical Science and Technology, Shahid Beheshti University, Daneshjou Boulevard, Velenjak, P.O. Box 1983969411, Tehran, Iran; Tel: +982129905803;

m tahmasian@sbu.ac.ir 


\section{Abstract}

Several neuroimaging studies have investigated localized aberrations in brain structure, function or connectivity in late-life depression, but the ensuing results are equivocal and often conflicting. Here, we provide a quantitative consolidation of neuroimaging in late-life depression using coordinate-based meta-analysis by searching multiple databases and tracing the relevant references up to March 2020. Our search revealed 3252 unique records, among which we identified 32 eligible whole-brain neuroimaging publications comparing 674 late-life depression patients with 568 healthy controls. The peak coordinates of group comparisons between patients and controls were extracted and then analyzed using activation likelihood estimation method. Our sufficiently powered analysis on all the experiments, and more homogenous subsections of the data (in-/decreases, experiments using functional imaging) revealed no significant convergent regional abnormality in late-life depression. This inconsistency might be due to experimental (e.g., choice of tasks, image modalities) and analytic flexibility (e.g., preprocessing and analytic parameters), distributed patterns of neural abnormalities, and heterogeneity of clinical populations (e.g., severity of late-life depression, age of onset). Our findings highlight the need for more reproducible research by using pre-registered and standardized protocols on more homogenous populations to identify potential consistent brain abnormalities in late-life depression.

Keywords: Late-life depression; Activation likelihood estimation; Functional magnetic resonance imaging; Voxel-based morphometry; Positron emission tomography. 


\section{Introduction}

Late-life depression (LLD) is defined as major depressive disorder (MDD) in patients over the age of 50 (Vaishnavi \& Taylor, 2006). This definition includes both late-onset depression (LOD), in which depression has started in later life, and early-onset depression (EOD), in which depression was first diagnosed in early adulthood and has continued into older ages. Recently, the global number of individuals with MDD who were older than 50 was estimated at about 60 million, with an estimated prevalence of $3.3 \%$ and $3.7 \%$ in the general population at the age ranges of $50-69$ and over 70 , respectively, being responsible for $2.5 \%-3.8 \%$ of years lost due to disability. With more aging of the populations, the global number of LLD patients has increased by 27.1\% from 2007 to 2017 (Global Burden of Disease Collaborative Network, 2018). LLD has detrimental effects on mental well-being of the patients, and can lead to cognitive dysfunctions, emotional impairments, and medical problems. Patients with LLD experience depressed mood, anxiety, feelings of guilt, hopelessness, or worthlessness, and have a restricted social functioning (Nelson, Clary, Leon, \& Schneider, 2005; Szanto et al., 2012). The cognitive dysfunction in these patients involves poor memory and concentration, slowed information processing, and attention deficits (Koenig, Bhalla, \& Butters, 2014). Moreover, LLD is associated with amyloid beta accumulation (Mahgoub \& Alexopoulos, 2016), and can increase the risk of Alzheimer's disease by 65\% (Diniz, Butters, Albert, Dew, \& Reynolds, 2013). In addition, depression in older adults increases the risk of developing/exacerbation of chronic medical diseases such as diabetes mellitus, cardiovascular diseases, and arthritis (Karakus \& Patton, 2011; Zivin, Wharton, \& Rostant, 2013). Older adults with LLD are also at a greater risk of mortality, both from suicide, and by an increased rate of cardiovascular diseases (Wei et al., 2019). Despite its detrimental effects, depression in older adults is underdiagnosed and poorly responds to treatment, highlighting the need for more clear understanding of its neurobiology (Manning, Wang, \& Steffens, 2019).

Aiming to unravel the neurobiological mechanisms of LLD, several neuroimaging studies have investigated localized abnormality in brain structure, function and connectivity, using voxel-based morphometry (VBM), task-based and resting-state functional magnetic resonance imaging ( $\mathrm{t}$-fMRI and rs-fMRI), and positron emission tomography (PET). Although these studies have advanced our understanding on neural correlates of LLD, they have often reported conflicting and heterogeneous results. For example, structural neuroimaging studies have variably reported cortical atrophy or hypertrophy of cortical regions such as the orbitofrontal cortex, precuneus, lateral temporal, cingulate or insula (Byun et al., 2016; Harada et al., 2016; Hwang et al., 2010; Oudega et al., 2014; Smith, Kramer, et al., 2009). In addition, functional neuroimaging studies have found abnormalities in various structures including the superior and inferior frontal gyri, precuneus, precentral gyrus, cingulate gyrus, parahippocampal cortex, cerebellum, or putamen (Bricenõ et al., 2015; Dombrovski, Szanto, Clark, 
Reynolds, \& Siegle, 2013; Liu et al., 2012; Smith, Kramer, et al., 2009; Yuan, Zhang, et al., 2008).

In the context of these inconsistent findings, meta-analytic approaches are valuable tools for quantitatively consolidating the effects observed across the published literature, in order to identify convergent findings (Müller et al., 2018; Tahmasian et al., 2019). Activation likelihood estimation (ALE) is a state-of-the-art coordinate-based meta-analysis (CBMA) method that identifies spatial convergence (or lack thereof) across findings of individual studies, and distinguishes true convergence from random overlap (Eickhoff, Bzdok, Laird, Kurth, \& Fox, 2012).

Of note, recent CBMAs on MDD, have failed to determine convergence in the primary analyses, but revealed effects for restricted sub-analyses of the data, which may hint at data heterogeneity (Gray, Müller, Eickhoff, \& Fox, 2020; Muller et al., 2017). And indeed, psychopathologically, LLD differs from depression in early adulthood e.g., by increased prevalence of cognitive dysfunction and somatic symptoms, but less dominant sadness feeling (Fiske, Wetherell, \& Gatz, 2009; Hegeman, Kok, van der Mast, \& Giltay, 2012), and a weaker response to the antidepressants (Tedeschini et al., 2011). In addition, imaging findings such as hippocampal atrophy, or microvascular lesions, are more common/severe in LLD patients (Aizenstein et al., 2016; McKinnon, Yucel, Nazarov, \& MacQueen, 2009). A CBMA exclusively focused on LLD may hence benefit from the improved homogeneity of patients' characteristics. Here, we used the ALE method on reported abnormalities derived from whole-brain structural and functional neuroimaging studies comparing LLD patients and healthy individuals, to provide a quantitative assessment of convergence across published literature.

\section{Methods}

This study was pre-registered on the International Prospective Register of Systematic Reviews (PROSPERO, code: CRD42019115872), and is reported according to the Preferred Reporting Items for Systematic Reviews and Meta-Analyses (PRISMA) statement (Moher, Liberati, Tetzlaff, Altman, \& Group, 2009). Here, we followed the most recent best-practice guidelines for neuroimaging metaanalyses (Müller et al., 2018; Tahmasian et al., 2019), to perform an ALE meta-analysis on neuroimaging studies comparing LLD patients with healthy control (HC) participants.

\section{Search and Study Selection}

We searched PubMed, Embase, Scopus, and Web of Science databases in March 2020 using the following search terms: (elderly OR geriatric OR "late life" OR "later life" OR "late onset" OR older OR "old age") AND (depress* OR MDD) AND ("voxel based morphometry" OR VBM OR "functional magnetic resonance imaging" OR fMRI OR "Positron-Emission Tomography" OR PET). The detailed search strategy for each database is reported in Table S1.. In addition to the records 
obtained by the search, we traced the references of relevant neuroimaging reviews/meta-analyses and the included studies.

After removing records duplicated in multiple databases, a total of 3253 unique records were screened by two independent reviewers (A.S., E.M.). The screening was performed in two stages, first using titles and/or abstracts, and then using full-text articles of potentially relevant records identified in the first stage.

We included original studies in which: (1) depression was diagnosed through an interview and using a standardized diagnostic criteria (i.e. Diagnostic and Statistical Manual of Mental Disorders [DSM], or International Classification of Diseases [ICD]), (2) patients had no major psychological or neurological comorbidities, such as dementia, stroke, Parkinson's disease, or psychosis, although comorbid anxiety was allowed due to its high co-occurrence with depression (Beekman et al., 2000), (3) patients were compared to elderly healthy control individuals, (4) all participants in both groups were $>50$ years old, (5) whole-brain structural or functional grey matter abnormalities were assessed using rs-fMRI, tfMRI, VBM, or PET, (6) analysis was not limited to a region of interest (ROI), and small volume correction (SVC) was not performed, as these approaches are biased toward finding significance in the respective regions, hence violating the assumption of ALE method that all voxels of the brain have a unified chance of being reported (Müller et al., 2018; Tahmasian et al., 2019), (7) patients were not part of an interventional study unless a baseline comparison with healthy controls was reported, (8) peak coordinates of significant findings were reported in Montreal Neurological Institute (MNI) or Talairach standard spaces, or were provided by authors upon our request. Of note, we excluded studies with null findings (Colloby et al., 2011; Delaloye et al., 2010; Marano et al., 2015; Patel et al., 2012; Sexton et al., 2012; Sin et al., 2018; Smith, Reynolds, et al., 2009; Vanyukov et al., 2015; Weber et al., 2012, 2010), as ALE method is aimed at identifying spatial convergence of findings, for which these studies contribute no data.

\section{Data Extraction}

Extracted data consisted of bibliographic information (first author, title, journal, country and institute), demographic and clinical data (number of participants, age, sex, age of onset, clinical status, medication status), study methodology (imaging modality, scanner field strength, task name and domain, software package, analysis approach, covariates, method of multiple comparison correction), and the peak coordinates of between-group experiments reported in each study. Notice that here, "study" refers to an individual publication, whereas "experiment" refers to individual contrasts reported within a "study" (e.g. LLD > HC, and HC > LLD), each yielding a distinct set of coordinates. Coordinates reported in Talairach space were transformed into MNI space (Lancaster et al., 2007), so that all the experiments are in the same reference space. If the applied reference space was not explicitly reported 
or provided by authors at our request, as suggested, we estimated it from the default settings of the software package used for normalization - i.e., FSL, SPM and FreeSurfer use MNI, while BrainVoyager uses Talairach (Müller et al., 2018; Tahmasian et al., 2019).

In ALE meta-analyses, including the data from overlapping samples causes spurious findings by improperly increasing the influence of that sample (Turkeltaub et al., 2012). Therefore, we took great care to avoid convergence over analyses performed on (partially) overlapping samples, both within and across papers. We reviewed the included studies for signs of overlap with other studies, by examining their team members, location of study, recruitment interval, and sample demographics, and merged their data in such cases. For the same reason, in both primary and complementary ALE analyses (see below), all coordinates from multiple experiments (i.e., in-/decreases, different imaging modalities, or different tasks) pertaining to the same subjects were merged, to make sure that in all analyses each sample is only represented by one experiment.

\section{Activation Likelihood Estimation}

The revised version of the ALE method (Eickhoff et al., 2012) was used to test the spatial convergence of the reported abnormalities, against the null hypothesis of randomly distributed findings across the brain. In this method, the peak coordinates, or foci, are convolved with 3D Gaussian probability distributions that have a full width at half maximum (FWHM) proportional to the sample size. This allows experiments with larger samples to have a greater statistical certainty in the meta-analysis. Next, for each experiment, the convolved foci are combined to generate per-experiment "modeled activation" (MA) maps. Subsequently, the MA maps for all the experiments included in the metaanalysis are combined into an ALE score map, representing the convergence of results at each particular location of the brain. The ALE score map is then statistically tested against a nulldistribution reflecting randomly distributed findings, to distinguish true convergence from by-chance overlap (Eickhoff et al., 2012; Turkeltaub et al., 2012). Finally, to avoid spurious findings, the resulting $\mathrm{p}$-values are corrected for multiple comparison using the stringent family-wise error correction at the cluster level (cFWE), thresholded at p $<0.05$ (Eickhoff, Laird, Fox, Lancaster, \& Fox, 2017). All these procedures were implemented using an in-house MATLAB script.

We performed separate ALE meta-analyses on different sets of experiments. In the primary analysis, to investigate all brain abnormalities regardless of their direction (in-/decreases) or imaging modality, we assessed the convergence across all the experiments. Next, we split the experiments by the direction of effect (HC > LLD or LLD > HC), imaging modalities (VBM, rs-fMRI, t-fMRI, or PET), task domains (cognitive vs. emotional), age of onset (LOD vs. EOD), or disease severity (acutely depressed vs. patients in remission), and performed complementary analyses on more homogeneous subsections of the data that fulfilled the requirement of representing at least 15 experiments for sufficient power 
(Eickhoff et al., 2016).

\section{Results}

We identified 32 eligible whole-brain neuroimaging papers comparing LLD patients with HC individuals (Albert, Gau, Taylor, \& Newhouse, 2017; Bobb et al., 2012; Bricenõ et al., 2015; Byun et al., 2016; Chen et al., 2012; De Asis et al., 2001; Dombrovski et al., 2013; Dumas \& Newhouse, 2015; Fang et al., 2015; Guo et al., 2013; Harada et al., 2018, 2016; Hou, Sui, Song, \& Yuan, 2016; C. M. Huang et al., 2019; Hwang et al., 2010; Lee, Liu, Wai, Ko, \& Lee, 2013; Li et al., 2020; Liu et al., 2012; Mah, Williams, Leung, Freel, \& Pollock, 2011; Oudega et al., 2014; Rao et al., 2015; Respino et al., 2019; Ribeiz et al., 2013; Smith, Kramer, et al., 2009; Takami, Okamoto, Yamashita, Okada, \& Yamawaki, 2007; Wang et al., 2008; Weisenbach et al., 2014; Wong et al., 2016; Xie et al., 2012; Yuan, Zhang, et al., 2008; Yuan, Zhu, et al., 2008; Yue, Jia, Hou, Zang, \& Yuan, 2015). Among these four groups of papers had (partially) overlapping samples, including (Bricenõ et al., 2015; Rao et al., 2015; Weisenbach et al., 2014), (Chen et al., 2012; Guo et al., 2013; Liu et al., 2012), (Harada et al., 2018, 2016), and (Yuan, Zhang, et al., 2008; Yuan, Zhu, et al., 2008). The data from these papers was merged, yielding 26 independent study populations with 674 LLD and 568 HC participants (Fig. 1).

VBM was used in nine experiments, t-fMRI in 11 experiments, rs-fMRI in seven experiments, and PET in two experiments. Task-based fMRI experiments were performed with various cognitive $(\mathrm{N}=$ 7) and emotional $(\mathrm{N}=6$ ) tasks. Of note, one t-fMRI study employed two different cognitive tasks and one emotional task, which were reported in separate papers (Bricenõ et al., 2015; Rao et al., 2015; Weisenbach et al., 2014). The demographic, clinical, and technical characteristics of the included studies are summarized in Tables 1 and S2.

Neither the primary nor the supplementary analyses revealed any significant regional convergence of neuroimaging findings for LLD (Table 2). In the primary analysis, 26 experiments representing all structural and functional abnormalities (in-/decreases) of the brain yielded $\mathrm{p}_{\mathrm{cFWE}}=0.828$. Pooling over 17 experiments reflecting increases (i.e. LLD > HC), and 19 experiments representing decreases (i.e. $\mathrm{HC}>$ LLD) separately, resulted in $\mathrm{p}_{\mathrm{CFWE}}=0.181$ and $\mathrm{p}_{\mathrm{cFWE}}=0.903$, respectively. Restricting the analysis to experiments using functional neuroimaging $(\mathrm{N}=20)$, or $\mathrm{fMRI}(\mathrm{N}=18)$, likewise, resulted in no significant convergence, with $\mathrm{p}_{\mathrm{cFWE}}=0.544$ and $\mathrm{p}_{\mathrm{cFWE}}=0.409$, respectively. Importantly, repeating all analyses with threshold-free cluster enhancement (TFCE), which is a potentially more lenient method of multiple comparison correction, again resulted in no significant convergence. Fig. 2 illustrates the spatial distribution for peak coordinates of all the experiments based on the effects direction. 


\section{Discussions}

Following the best-practice guidelines for conducting meta-analyses, we observed no significant convergence of regional brain abnormalities in both primary and complementary analyses. The lack of convergence indicates that the current literature of LLD does not support consistent, localized pathophysiology in spite of the more homogeneous nature of LLD relative to the entirety of MDD. Aspects that may have contributed to this null-effect will be discussed as follows.

\section{Heterogeneity of neuroimaging methodology on LLD}

The studies included in this meta-analysis used a wide range of imaging acquisition techniques, preprocessing, and analytic methods to explore various neurobiological features of LLD. The most notable source of heterogeneity across the included studies was the different applied structural and functional imaging modalities including VBM, rs-fMRI, t-fMRI, or PET. Considerable heterogeneity was also evident further within functional neuroimaging (i.e., rs-fMRI, t-fMRI, or PET) experiments, which constituted $76 \%$ of our included experiments, as the complementary analyses limited to these experiments also showed no convergent finding. The primary reason for this could be that in each experiment the subjects were engaged in different mental states, i.e., resting condition (30\%), or doing a variety of cognitive $(30 \%)$ or emotional (23\%) task paradigms (e.g., n-back, stop-signal, Go/No-Go, word generation, emotional judgement of faces) with different visual or auditory stimuli, naturally involving distinct neural processes. We can appreciate how this can influence the findings, in three of our included studies that used different tasks (i.e., facial emotion perception, Go/No-Go, and semantic list learning) on the same sample, and found different, and in some regions conflicting results (Bricenõ et al., 2015; Rao et al., 2015; Weisenbach et al., 2014). In rs-fMRI experiments, an additional source of heterogeneity may be the various applied analytical approaches, each designed to capture a conceptually different aspect of whole-brain functional connectivity. For instance, while Amplitude of Low Frequency Fluctuations (ALFF; 11\%) assesses the regional intensity of oscillatory fluctuations in a voxel's time series (Zou et al., 2008), Regional Homogeneity (ReHo; 11\%) calculates the correlation of a voxel's time series with that of its nearest voxels (Zang, Jiang, Lu, He, \& Tian, 2004), and voxel-wise Degree Centrality (DC; 3\%) is a graph theory measure that represents the total weights of connections for a given voxel (Rubinov \& Sporns, 2010). In addition, in both structural and functional neuroimaging studies, preprocessing steps and analytical flexibility regarding design matrices, multiple comparison correction methods, software packages, and even operating systems introduces another level of heterogeneity across studies (Glatard et al., 2015; Poldrack et al., 2017). Of note, the methodological flexibility of neuroimaging studies is so diverse, that in a recent study, among 70 independent teams analyzing the same fMRI dataset, not even two teams chose identical analytic workflows (Botvinik-Nezer et al., 2020). 
The experimental and analytical flexibility of neuroimaging methods is a double-edge sword, as it allows for investigating many diverse aspects of neurobiology, but can also lead to spurious/false positive findings. This is particularly true for low-powered studies in the presence of liberal thresholding and selective reporting (Button et al., 2013). Low-powered studies are inherently prone to an increased proportion of false positive findings, i.e., small positive predictive value (Ioannidis, 2005). In addition, they are more likely to fail to identify the effects, particularly when they are small, and in a research community that values statistical significance, are incentivized to adopt questionable research practices, or "p-hacking", to "fish" for significant findings (Button et al., 2013). For instance, they might choose to report the results that are rather liberal and uncorrected for multiple comparisons, as in 31\% of our included studies. In this case, and particularly given that the sample sizes in our included studies were in the low to moderate range (median: 45, range: 11-96), it is wellconceivable that some of the reported foci included in our meta-analysis were naturally non-replicable.

As ALE analyses with very few number experiments are unstable and could be potentially driven by a single experiment, with the exception of complementary analyses limited to different directions of the effect and the functional experiments, we were unable to test the convergence across more homogeneous sets of experiments, limited to e.g. structural experiments, specific task domains/paradigms, specific methods of rs-fMRI analysis, or LOD/EOD patients (Eickhoff et al., 2016). Of note, while we acknowledge that pooling over heterogeneous data is debateful, we should mention that a trade-off between homogeneity and the number of experiments is inherent to all metaanalytic approaches, including CBMA. There is generally no simple answer on the optimal balance between the two, but the most important determining factor is the scientific question of interest (Tahmasian, Zarei, et al., 2018).

\section{Beyond localization of grey matter abnormalities}

Another interpretation of our finding, would be that LLD may be associated with distributed brain network abnormalities, rather than localized ones. In this case, neuroimaging studies aimed at localizing the effects would each pick up on different (due to noise and flexibility, cf. section 4.1) distinct parts of the disturbed, distributed network, resulting in poor convergence of local findings (Kharabian Masouleh, Eickhoff, Hoffstaedter, Genon, \& Alzheimer's Disease Neuroimaging Initiative, 2019). Of note, in ALE meta-analyses all seed-based connectivity studies are excluded in order to ensure that all the voxels have the same a priori chance of being reported (Müller et al., 2018; Tahmasian et al., 2019). In addition, ALE meta-analysis is a method of finding localized convergent abnormalities in the brain structure, function or connectivity, and hence, in this meta-analysis we were unable to test the network alterations associated with LLD. The functional connectivity studies on LLD have been reviewed elsewhere (Manning et al., 2019; Tadayonnejad \& Ajilore, 2014), indicating 
increased functional connectivity in the default mode network (DMN) and salience network, but decreased functional connectivity in executive control network, in addition to decreased network efficiency, reduced network strength, and increased long-range connections in LLD patients.

In addition, beyond the grey matter and functional abnormalities in LLD, its pathophysiology is also associated with micro-/macrostructural white-matter abnormalities. A meta-analysis on diffusion tensor imaging (DTI) studies on LLD, reported lower fractional anisotropy of dorsolateral prefrontal cortex and uncinate fasciculus, indicating a possible role for the disruption of frontal and frontal-tolimbic white matter tracts in pathogenesis of LLD (Wen, Steffens, Chen, \& Zainal, 2014). Besides, white-matter hyperintensities (WMHs), which are areas of increased intensity in T2w images, and normally occurring in elderly individuals, are associated with an increased risk of LLD (van Agtmaal, Houben, Pouwer, Stehouwer, \& Schram, 2017), particularly when located in cingulum, uncinate fasciculus, superior longitudinal fasciculus, frontal lobe, and temporal lobe (Alexopoulos, 2019). Of note, the increased severity of WMHs in LLD patients, along with a higher rate of cerebrovascular risk factors, and the evidence for other cerebrovascular lesions in these patients (e.g. lacunae, cerebral microbleeds, and cerebral microinfarctions), has originated the idea that LLD, and more specifically LOD, may to some extent have a vascular etiology (Alexopoulos, 2019).

\section{Depression is a heterogeneous diagnosis}

Our meta-analysis had an improved homogeneity of study populations compared to previous metaanalyses on MDD (Gray et al., 2020; Muller et al., 2017), by being limited to older adults. However, further differences in study populations exist that can contribute to additional heterogeneity across studies regarding, with regard to e.g. medication status, clinical status (actue or chronic), severity of disorder, age of onset, sex disribution, age cut-offs used to define LLD, and existance of comorbidities. Most importantly, there is overwhelming evidence on the differences of LOD and EOD in many aspects, such as clinical symptoms, genetic susceptibility, microvascular abnormalities, and neuroimaging findings (Tittmann et al., 2014). In addition, treatment of depression can lead to changes in the brain reorganization, such as normalization of DMN connectivity (Delaveau et al., 2011; Gudayol-Ferre, Pero-Cebollero, Gonzalez-Garrido, \& Guardia-Olmos, 2015). Moreover, the included studies had a wide range of sex distributions, with four studies limited to a only males/females, and indeed sex differences are evident in the neurobiology of LLD (Bricenõ et al., 2015; Lavretsky et al., 2004), as well as normal structure and function of the brain (Ritchie et al., 2018).

In addition, MDD, in itself, is a heterogeneous diagnostic category with regard to the individual differences in symptom profiles, genetic etiologies, comorbidities, and treatment outcomes (Goldberg, 2011; Lynch, Gunning, \& Liston, 2020). Considering the symptom profiles alone, with the DSM criteria for MDD diagnosis, more than 200 unique combinations of symptoms are theoretically 
possible. In practice, different clusters of symptoms commonly co-occur, creating different classic clinical subtypes of depression, such as atypical, melancholic, psychotic, catatonic, anxious, or seasonal depression (Lynch et al., 2020). While more homogenous than MDD in its entirety, LLD also represents a heterogenous diagnostic category. Using clinical variables, five distinct subtypes of LLD, including 'mild pure depression', 'severe pure depression', 'amnestic depression', 'frail-depressed, physically dominated', and 'frail-depressed, cognitively dominated' have been identified, which interestingly correlate with the rate of remission and mortality (Lugtenburg et al., 2020).

Beyond clinical characteristics, MDD is also biologically heterogeneous, meaning that different mechanistic pathways exist and converge to a common phenotype, i.e., depression. Data-driven studies on biochemical, genetics, or neuroimaging data have identified various biological subtypes of depression (for review see Beijers et al., 2019). Importantly, in a recent study on 1188 depressed patients, resting-state functional connectivity and symptom profiles were used to identify four subtypes of depression with distinct patterns of dysfunctional connectivity in limbic and frontostriatal networks. Two of these subtypes were related to anhedonia and psychomotor retardation, while the other two were characterized by anxiety and insomnia, and interestingly, these subtypes predicted the response to repetitive transcranial magnetic stimulation treatment with a high accuracy (Drysdale et al., 2017). It may be that LLD is also biologically heterogeneous, in which case we can argue that our lack of meta-analytic findings, could in part be attributed to the varying combinations of subtypes included in each study and the ensuing dilution of subtype-specific effects.

\section{Overview of previous neuroimaging meta-analyses on LLD}

Previous CBMAs on LLD have solely focused on the structural brain abnormalities, and reported conflicting results (Boccia, Acierno, \& Piccardi, 2015; Du et al., 2014). They have identified convergence in a variety of regions including the putamen, hippocampus, amygdala, parahippocampal gyrus, medial frontal gyrus, subcallosal gyrus, and lingual gyrus (Du et al., 2014), as well as the amygdala, thalamus, cingulate gyrus, precuneus, superior frontal gyrus, and ventromedial frontal cortex (Boccia et al., 2015). According to the recent best-practice guidelines for neuroimaging metaanalyses, there are arguably some methodological issues in these studies. Firstly, they lacked sufficient statistical power, as only nine studies (including four studies with null results) were included in (Du et al., 2014), and only six studies (nine experiments) were included in (Boccia et al., 2015), both below the number required for a robust meta-analysis $(>15)$, and making their results susceptible to the influence of a single experiment (Eickhoff et al., 2016). Of note, the number of structural neuroimaging experiments included in our meta-analysis $(\mathrm{N}=9)$ was not sufficient, and we forego a separate analysis on these experiments. Secondly, in (Du et al., 2014) effect size signed differential mapping (ES-SDM) was utilized, which is an alternative CBMA method, and considered as statistically 
more lenient compared to ALE, and is also different by taking studies with null findings into account. Thirdly, both meta-analyses used liberal methods of multiple comparison correction, and were susceptible to false-positive findings. Specifically, (Du et al., 2014) reported the results with uncorrected threshold of $\mathrm{p}=0.005$ and $\mathrm{Z}>1$, and (Boccia et al., 2015) used false discovery rate (FDR), which is more liberal compared to cFWE, and is no longer recommended in ALE metaanalyses (Eickhoff et al., 2016; Müller et al., 2018; Tahmasian et al., 2019).

\section{Recommendations and future directions}

This study, and previous meta-analyses on MDD (Gray et al., 2020; Muller et al., 2017), have shown inconsistency of findings across neuroimaging studies on (late-life) depression. Of note, this is not limited to depression, and has also been observed in e.g. insomnia disorder, Parkinson's disease, migraine, attention deficit hyperactivity disorder, self-injurious thoughts, or the impact of COMT Val158Met allele on brain activation related to working memory (Giehl, Tahmasian, Eickhoff, \& van Eimeren, 2019; X. Huang, Rootes-Murdy, Bastidas, Nee, \& Franklin, 2020; Nickl-Jockschat, Janouschek, Eickhoff, \& Eickhoff, 2015; Samea et al., 2019; Sheng et al., 2020; Tahmasian, Noori, et al., 2018).

In order to differentiate a true lack of localizable effects from between-study variability, we recommend that future studies on (late-life) depression to (1) use larger sample sizes ideally through collaborations to ameliorate site-idiosyncrasies, (2) openly share their data to allow replication and future integration, (3) standardize experimental, preprocessing, and analytical methods or at least establish replicability through providing sufficient detail or code (Button et al., 2013), (4) focus more on multivariate analytical approaches, which are better equipped to detect abnormal brain networks (Kharabian Masouleh et al., 2019), (5) consider data-driven approaches to accommodate potential biological subtypes, and (6) pre-register protocols for individual studies, as well for meta-analyses to reduce publication bias.

Of note, with more neuroimaging studies published on LLD, future updates to this meta-analysis would be able to perform additional subgroup analyses, and identify convergence across more homogenous data. In addition, CBMAs are based on limited spatial data, i.e., the peak coordinates of significant regions between groups, and are hence less powerful compared to the alternative imagebased meta-analysis, which consolidates the findings of studies using their unthresholded statistical parametric maps (Salimi-Khorshidi, Smith, Keltner, Wager, \& Nichols, 2009). Here, due to the sparsity of this data, we were unable to do an image-based meta-analysis on LLD, and we encourage authors to submit their statistical maps to open data sharing platforms such as NeuroVault repository (https://neurovault.org/; Gorgolewski et al., 2015), so that this more powerful method of analysis is possible in the future. 


\section{Conclusions}

In summary, following current best-practice protocols, our pre-registered and sufficiently powered analyses demonstrated the absence of any consistent local abnormality in LLD. The combination of subtypes and distributed patterns, in addition to protocol heterogeneity and selective reporting may explain the lack of any localizable convergence for LLD. Our findings highlight the need for using standard methodology of future neuroimaging studies on (late-life) depression, toward more reproducible, pre-registered and clearly reported studies, recruiting more homogenous populations, and aimed at identifying both localized and distributed abnormalities of the brain.

\section{Acknowledgements}

None.

\section{Author Contributions}

MT and AS formed the idea and designed the study. AS and EM contributed to the literature search and data extraction, based on suggestions from MT and SBE. AS and MT performed the analyses. SBE contributed algorithms and additional supervision. AS drafted the manuscript. MT, SBE, MZ, and EM revised and approved the paper.

\section{Conflict of Interest}

None of the authors have a conflict of interest to declare. 


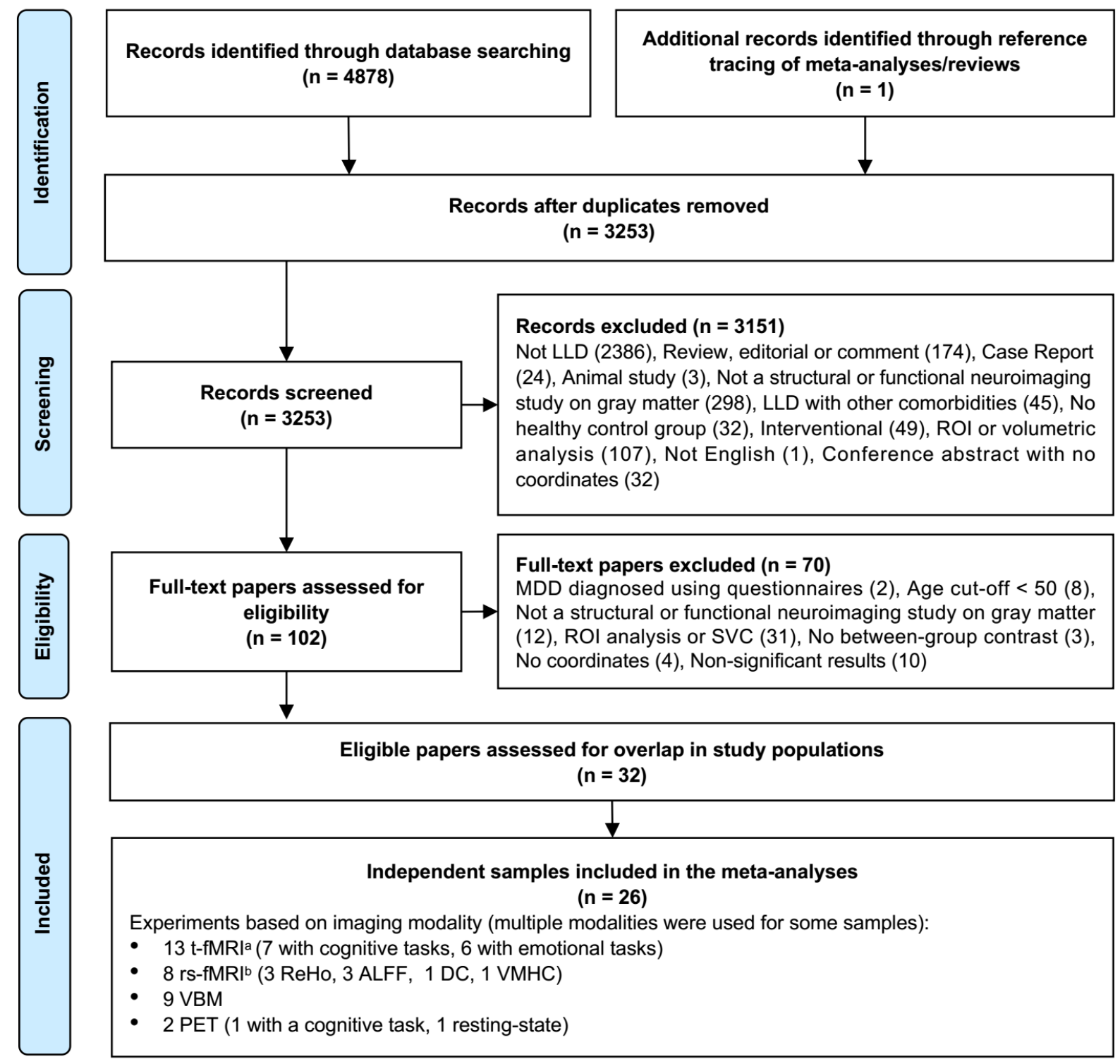

Fig. 1. Study selection flowchart. LLD: late-life depression; MDD: major depressive disorder; ROI: region of interest; SVC: small volume correction; rs-fMRI: resting-state functional magnetic resonance imaging; t-fMRI: task-based functional magnetic resonance imaging; ReHo: regional homogeneity; ALFF: amplitude of low frequency fluctuations; DC: voxel-wise degree centrality; VMHC: voxel-mirrored homotopic connectivity; VBM: voxel-based morphometry; PET: positron emission tomography.

${ }^{\mathrm{a}}$ Two different types of cognitive tasks and one emotional task were used for the same sample.

${ }^{\mathrm{b}}$ Both ReHo and ALFF were used in the same sample. 


\section{A. Reported coordinates of abnormalities in LLD}
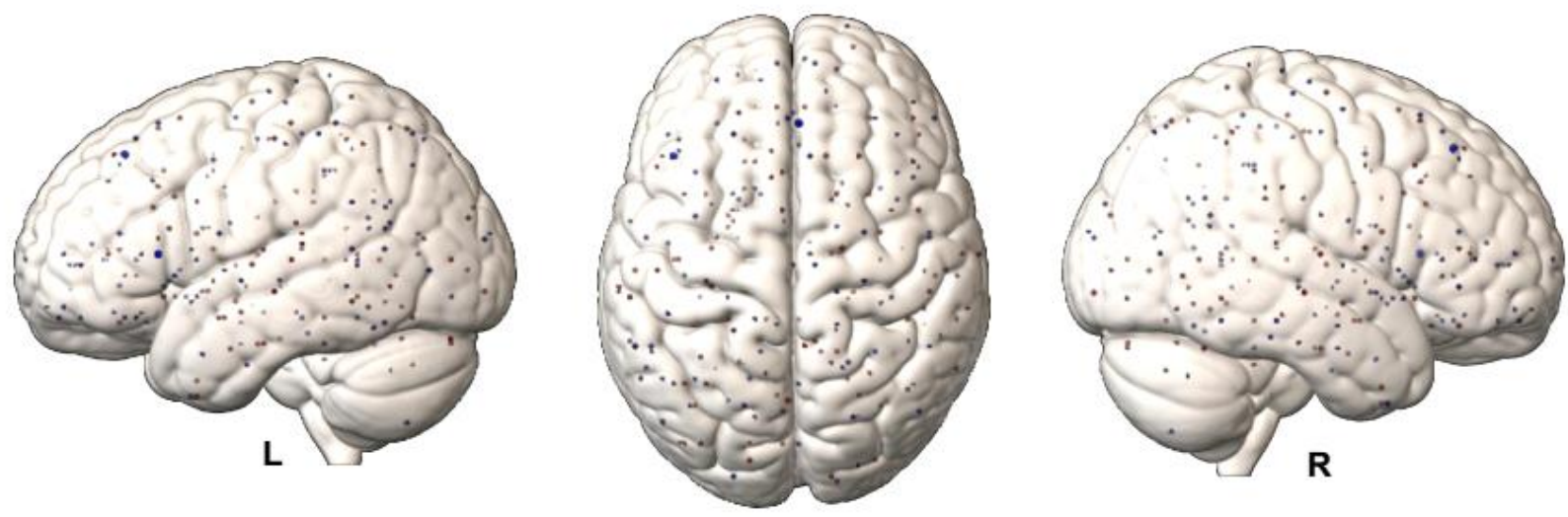

\section{B. Modeled activation maps of abnormalities in LLD}
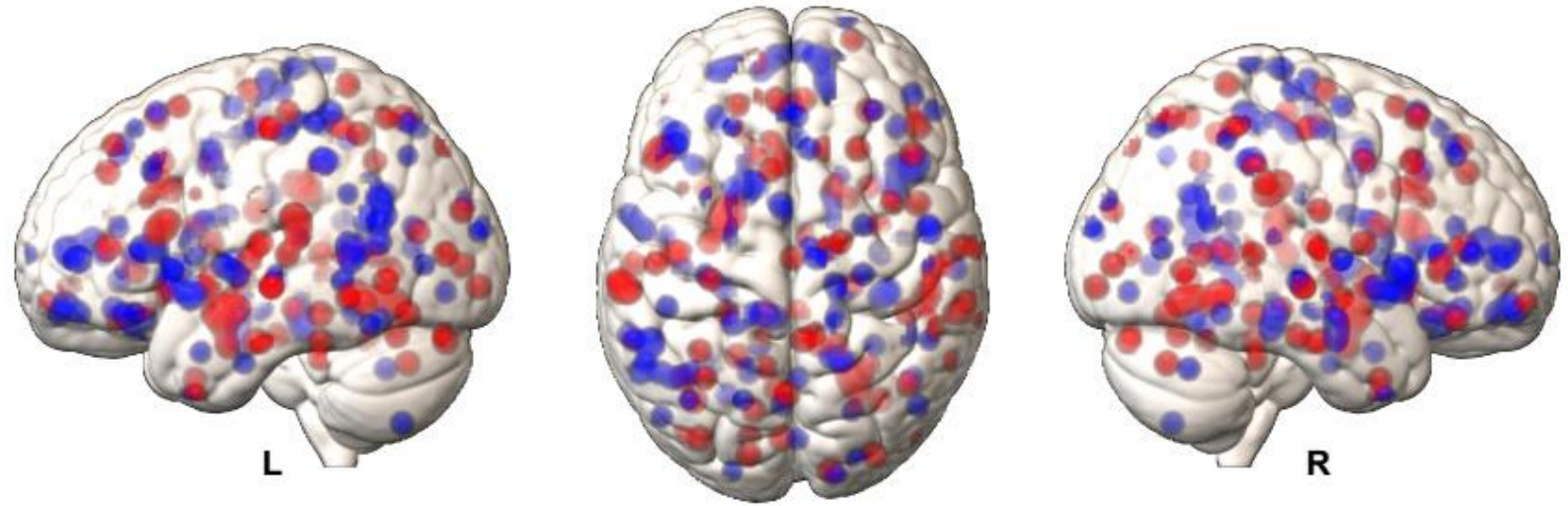

Fig. 2. The activation likelihood estimation meta-analysis steps. Panel A shows the distribution of reported coordinates reflecting structural/functional brain alterations in patients with late-life depression (LLD) compared to healthy control (HC) subjects. Panel B displays the modeled activation maps, obtained by combining the reported coordinates modeled as 3D Gaussian distributions ( $\mathrm{red}=\mathrm{LLD}>\mathrm{HC}$, blue $=\mathrm{HC}>\mathrm{LLD}$ ). Statistical testing against null-distribution, corrected for multiple comparisons using family-wise error correction at the cluster level, showed no convergence of the reported abnormalities. 
Table 1. Characteristics of studies included in the meta-analysis.

\begin{tabular}{|c|c|c|c|c|c|c|c|c|c|c|}
\hline & \multirow[t]{2}{*}{ First Author (Year) ${ }^{\mathrm{a}}$} & \multicolumn{2}{|c|}{ Number ( $\%$ female) } & \multicolumn{2}{|c|}{$\begin{array}{l}\text { Age mean } \pm S D / \text { median } \\
(I Q R)\end{array}$} & \multirow[t]{2}{*}{$\begin{array}{l}\text { Acute } \\
\text { Depresssion }\end{array}$} & \multirow[t]{2}{*}{$\begin{array}{l}\text { Anti- } \\
\text { depressants }\end{array}$} & \multirow[t]{2}{*}{$\begin{array}{l}\text { Age of } \\
\text { Onset }\end{array}$} & \multirow[t]{2}{*}{$\begin{array}{l}\text { Neuroimaging } \\
\text { Technique }\end{array}$} & \multirow[t]{2}{*}{ Task } \\
\hline & & LLD & $\mathrm{HC}$ & LLD & HC & & & & & \\
\hline 1 & Albert, K (2017) & $12(100 \%)$ & $21(100 \%)$ & $62.4 \pm 5.7$ & $60.6 \pm 6.8$ & No & Variable & n.r. & t-fMRI & emotion dot probe \\
\hline 2 & Bobb, DS (2012) & $15(80 \%)$ & $13(69 \%)$ & $60.7 \pm 4.7$ & $62.0 \pm 5.3$ & Yes & Off & n.r. & $\mathrm{t}$-fMRI & stop signal task \\
\hline \multirow[t]{3}{*}{3} & Bricenõ, EM (2015) & $26(46 \%)$ & $25(48 \%)$ & $65.4 \pm 8.1$ & $68.1 \pm 8.2$ & Yes & Variable & EOD & t-fMRI & $\begin{array}{l}\text { facial emotion } \\
\text { perception }\end{array}$ \\
\hline & Rao, JA (2015) & 24 (n.r.) & 23 (n.r.) & $66.8 \pm 8.2$ & $67.9 \pm 8.1$ & & & & t-fMRI & go/no-go \\
\hline & Weisenbach, SL (2014) & $24(58 \%)$ & $23(43 \%)$ & $66.8 \pm$ n.r. & $67.9 \pm$ n.r. & & & & t-fMRI & semantic list learning \\
\hline 4 & Byun, MS (2016) & $29(72 \%)$ & $27(48 \%)$ & $71.6 \pm 5.0$ & $68.7 \pm 6.0$ & Variable & On & LOD & VBM & \\
\hline \multirow[t]{3}{*}{5} & Chen, JD (2012) & $16(60 \%)$ & $15(60 \%)$ & $67.5 \pm 6.1$ & $64.9 \pm 3.7$ & Yes & Drug-naive & LOD & rs-fMRI (ReHo) & \\
\hline & Guo, W (2013) & $17(60 \%)$ & $16(60 \%)$ & $67.5 \pm 6.1$ & $64.9 \pm 3.7$ & & & & rs-fMRI (ALFF) & \\
\hline & Liu, F (2012) & $15(60 \%)$ & $15(60 \%)$ & $67.5 \pm 6.1$ & $64.9 \pm 3.7$ & & & & rs-fMRI (ReHo) & \\
\hline 6 & De Asis, J (2001) & $6(0 \%)$ & $5(0 \%)$ & $70.7 \pm$ n.r. & $67.6 \pm$ n.r. & Yes & Variable & n.r. & PET & \\
\hline 7 & $\begin{array}{l}\text { Dombrovski, AY } \\
\text { (2013) }\end{array}$ & $31(58 \%)$ & $20(60 \%)$ & $66.3 \pm 5.8$ & $70.7 \pm 8.7$ & Variable & Variable & n.r. & t-fMRI & $\begin{array}{l}\text { probabilistic reversal } \\
\text { learning }\end{array}$ \\
\hline 8 & Dumas, JA (2015) & 11 (n.r.) & 12 (n.r.) & $73.3 \pm 3.3$ & $72.6 \pm 5.7$ & n.r. & Variable & Variable & $\mathrm{t}$-fMRI & n-back \\
\hline 9 & Fang, J (2015) & $20(00 \%)$ & $18(0 \%)$ & $59.2+3.7$ & $59.1 \pm 7.5$ & Variable & n.r. & n.r. & $\begin{array}{l}\text { VBM, rs-fMRI } \\
\text { (ALFF) }\end{array}$ & \\
\hline
\end{tabular}




\begin{tabular}{|c|c|c|c|c|c|c|c|c|c|c|}
\hline \multirow[t]{2}{*}{10} & Harada, K (2016) & $45(67 \%)$ & $61(57 \%)$ & $60.2 \pm 8.2$ & $62.9 \pm 7.6$ & Yes & Variable & n.r. & VBM & \\
\hline & Harada, K (2018) & $16(63 \%)$ & $30(62 \%)$ & $\begin{array}{l}56(53.5- \\
65.5)\end{array}$ & $58(54-67)$ & & & & VBM & \\
\hline 11 & Hou, Z (2016) & $31(67 \%)$ & $37(51 \%)$ & $68.0 \pm 6.0$ & $65.2 \pm 7.5$ & Yes & Off & LOD & $\begin{array}{l}\text { rs-fMRI } \\
\text { (VMHC) }\end{array}$ & \\
\hline 12 & Huang, CM (2019) & $55(69 \%)$ & $40(62 \%)$ & $66.3 \pm 5.4$ & $68.1 \pm 5.3$ & Yes & Variable & LOD & t-fMRI & $\begin{array}{l}\text { color-word emotional } \\
\text { Stroop }\end{array}$ \\
\hline 13 & Hwang, JP (2010) & $70(00 \%)$ & $26(0 \%)$ & $79.4 \pm 5.3$ & $79.5 \pm 4.3$ & Yes & n.r. & LOD & VBM & \\
\hline 14 & Lee, TW (2013) & $14(21 \%)$ & $14(35 \%)$ & $65.1 \pm 4.9$ & $64.8 \pm 4.2$ & Yes & On & LOD & t-fMRI & n-back \\
\hline 15 & Li, J (2020) & $50(62 \%)$ & $33(48 \%)$ & $66.6 \pm 0.7$ & $67.2 \pm 0.8$ & Yes & Variable & Variable & rs-fMRI (DC) & \\
\hline 16 & Mah, L (2011) & $5(0 \%)$ & $8(0 \%)$ & $66 \pm 6$ & $69 \pm 5$ & n.r. & Drug-naive & n.r. & t-fMRI & $\begin{array}{l}\text { emotional judgment of } \\
\text { faces }\end{array}$ \\
\hline 17 & Oudega, ML (2014) & $55(65 \%)$ & $23(52 \%)$ & $72.3 \pm 7.8$ & $70.3 \pm 6.3$ & Yes & Off & Variable & VBM & \\
\hline 18 & Respino, M (2019) & $33(63 \%)$ & $43(58 \%)$ & $72.2 \pm 6.6$ & $73.4 \pm 6.5$ & Yes & Off & n.r. & rs-fMRI & \\
\hline 19 & Ribeiz, SRI (2013) & $30(76 \%)$ & $22(77 \%)$ & $70.7 \pm 6.5$ & $70.4 \pm 7.5$ & n.r. & n.r. & Variable & VBM & \\
\hline 20 & Smith, GS (2009) & $16(62 \%)$ & $13(61 \%)$ & $65.3 \pm 9.1$ & $67.4 \pm 7.4$ & n.r. & Off & n.r. & VBM, PET & \\
\hline 21 & Takami, H (2007) & $10(70 \%)$ & $10(60 \%)$ & $62.5 \pm 9.1$ & $67.6 \pm 9.7$ & No & Variable & LOD & t-fMRI & word generation \\
\hline 22 & Wang, L (2008) & $27(44 \%)$ & $20(60 \%)$ & $70.0 \pm 5.7$ & $73.1 \pm 5.1$ & Variable & Variable & LOD & t-fMRI & emotional oddball task \\
\hline 23 & Wong, NM (2016) & $31(54 \%)$ & $23(60 \%)$ & $67.4 \pm 5.4$ & $67.1 \pm 4.7$ & n.r. & On & LOD & t-fMRI & emotion processing \\
\hline 24 & Xie, C (2012) & $18(77 \%)$ & $25(48 \%)$ & $68.6 \pm 6.8$ & $74.2 \pm 8.2$ & Yes & Variable & n.r. & VBM & \\
\hline
\end{tabular}




\begin{tabular}{|c|c|c|c|c|c|c|c|c|c|}
\hline \multirow{2}{*}{25} & Yuan, Y (2008) & $18(55 \%)$ & $14(50 \%)$ & $67.2 \pm 7.3$ & $67.1 \pm 4.8$ & No & Off & LOD & rs-fMRI (ReHo) \\
\hline & Yuan, Y (2008) & $19(52 \%)$ & $16(50 \%)$ & $67.2 \pm 7.3$ & $67.1 \pm 4.8$ & & & & VBM \\
\hline 26 & Yue, Y (2015) & $16(50 \%)$ & $16(50 \%)$ & $68.1 \pm 5.2$ & $68.2 \pm 4.6$ & Yes & Drug-naive & LOD & rs-fMRI (ALFF) \\
\hline
\end{tabular}

$\mathrm{LLD}=$ late-life derpession; $\mathrm{HC}=$ healthy control; $\mathrm{SD}=$ standard deviaiton; n.r. $=$ not reported; $\mathrm{EOD}=$ early-onset depression; $\mathrm{LOD}=$ late-onset depression; t-fMRI = task-based functional magnetic resonance imaging; rs-fMRI = resting-state functional magnetic resonance imaging; VBM = voxel-based morphometry; PET = positron-emission tomography; ReHo = regional homogeneity; ALFF = amplitude of low frequency fluctuations; DC = voxel-wise degree centrality; VMHC = voxel-mirrored homotopic connectivity.

${ }^{a}$ Publications with overlapping samples are grouped together 
Table 2. Results of ALE meta-analyses on patients with late-life depression compared to healthy subjects by modality and direction of effect.

\begin{tabular}{lllll}
\hline Imaging modality & Contrast & $\begin{array}{l}\text { Number of } \\
\text { experiments }\end{array}$ & \multicolumn{2}{l}{ p-value } \\
\cline { 3 - 5 } & & TFCE & cFWE \\
\hline Structural or functional (VBM, PET, fMRI) & - & 26 & 0.568 & 0.828 \\
\cline { 2 - 5 } & HC > LLD & 19 & 0.755 & 0.903 \\
\cline { 2 - 5 } & LLD > HC & 17 & 0.136 & 0.181 \\
\hline Functional (PET or fMRI) & - & 20 & 0.216 & 0.544 \\
\hline fMRI (task-based or resting-state) & - & 18 & 0.183 & 0.409 \\
\hline
\end{tabular}

$\mathrm{VBM}=$ voxel-based morphometry; $\mathrm{PET}=$ positron-emission tomography fMRI $=$ functional magnetic resonance imaging; LLD = late-life depression; HC = healthy control; TFCE = thresholdfree cluster enhancement; $\mathrm{cFWE}=$ family-wise error at cluster level. 
Table S1. Search query used in each database.

\begin{tabular}{ll}
\hline Database & Search Query \\
\hline PubMed & ("voxel based morphometry" OR VBM OR "functional magnetic \\
& resonance imaging" OR fMRI OR "Positron-Emission Tomography" \\
& OR PET) AND (elderly[tiab] OR geriatric[tiab] OR "late life"[tiab] OR \\
& "later life"[tiab] OR "late onset"[tiab] OR older[tiab] OR "old \\
& age"[tiab]) AND (depress* OR MDD) \\
\hline Embase & ('voxel based morphometry'/exp OR 'voxel based morphometry' OR \\
& vbm OR 'functional magnetic resonance imaging'/exp OR 'functional \\
& magnetic resonance imaging' OR 'fmri'/exp OR fmri OR 'positron- \\
& emission tomography'/exp OR 'positron-emission tomography' OR \\
& 'pet'/exp OR pet) AND (elderly:ti,ab OR geriatric:ti,ab OR 'late \\
& life':ti,ab OR 'later life':ti,ab OR 'late onset':ti,ab OR older:ti,ab OR 'old \\
& age':ti,ab) AND (depress* OR mdd) \\
\hline Scopus ${ }^{\mathrm{a}}$ & ("voxel based morphometry" OR VBM OR "functional magnetic \\
& resonance imaging" OR fMRI OR "Positron-Emission Tomography" \\
& OR PET) AND (elderly OR geriatric OR "late life" OR "later life" OR \\
& "late onset" OR older OR "old age") AND (depress* OR MDD) \\
\hline Web of & ("voxel based morphometry" OR VBM OR "functional magnetic \\
Knowledge ${ }^{b}$ & resonance imaging" OR fMRI OR "Positron-Emission Tomography" \\
& OR PET) AND (elderly OR geriatric OR "late life" OR "later life" OR \\
& "late onset" OR older OR "old age") AND (depress* OR MDD) \\
\hline
\end{tabular}

${ }^{a}$ In title, abstract or keywords.

b In 'topic' 
Table S2. Technical details of studies included in the meta-analysis.

\begin{tabular}{|c|c|c|c|c|c|c|c|}
\hline & First Author (Year) ${ }^{a}$ & $\begin{array}{l}\text { Scanner } \\
\text { Field } \\
\text { Strength }\end{array}$ & Software & Multiple Comparison Correction & Covariates & $\begin{array}{l}\text { Coordinates } \\
\text { Space }\end{array}$ & $\begin{array}{l}\text { Source of } \\
\text { Coordinates }\end{array}$ \\
\hline 1 & Albert, K (2017) & $3 \mathrm{~T}$ & SPM & AlphaSim $(\mathrm{k}=58, \mathrm{p}<0.000001)$ & n.r. & MNI & Figure 3 \\
\hline 2 & Bobb, DS (2012) & $3 \mathrm{~T}$ & FSL & FWE & n.r. & MNI & Table 2 \\
\hline \multirow[t]{3}{*}{3} & Bricenõ, EM (2015) & $3 \mathrm{~T}$ & FSL & AlphaSim $(\mathrm{k}=55, \mathrm{p}<0.005)$ & n.r. & MNI & Table 3 \\
\hline & Rao, JA (2015) & $3 \mathrm{~T}$ & FSL, SPM & AlphaSim $(\mathrm{k}=264 \mathrm{~mm} 3, \mathrm{p}<0.003)$ & n.r. & MNI & Table 2 \\
\hline & Weisenbach, SL (2014) & $3 \mathrm{~T}$ & SPM & AlphaSim $(\mathrm{k}=264 \mathrm{~mm} 3, \mathrm{p}<0.003)$ & n.r. & MNI & Table 2 \\
\hline 4 & Byun, MS (2016) & $3 \mathrm{~T}$ & SPM & FWE $(k=100)$ & age, gender, education level & $\mathrm{MNI}$ & Table S3 \\
\hline \multirow[t]{3}{*}{5} & Chen, JD (2012) & $1.5 \mathrm{~T}$ & SPM & AlphaSim $(\mathrm{k}=675 \mathrm{~mm} 3, \mathrm{p}<0.005)$ & age, voxel-wise GM volume & MNI & Table 2 \\
\hline & Guo, W (2013) & $1.5 \mathrm{~T}$ & SPM & FDR & n.r. & MNI & Table 2 \\
\hline & Liu, F (2012) & $1.5 \mathrm{~T}$ & SPM & $\begin{array}{l}\text { Not Corrected }(\mathrm{k}=1483 \mathrm{~mm} 3, \mathrm{p}< \\
0.005)\end{array}$ & age, voxel-wise GM volume & $\mathrm{MNI}$ & Table 2 \\
\hline 6 & De Asis, J (2001) & n.a. & SPM & Not Corrected $(\mathrm{p}<0.01)$ & global rCBF & Talairach & Text \\
\hline 7 & Dombrovski, AY (2013) & $3 \mathrm{~T}$ & AFNI & AlphaSim $(\mathrm{k}=67)$ & n.r. & MNI & Author \\
\hline 8 & Dumas, JA (2015) & $3 \mathrm{~T}$ & SPM & Not Corrected $(\mathrm{k}=200)$ & n.r. & MNI & Figure 1 \\
\hline 9 & Fang, J (2015) & $1.5 \mathrm{~T}$ & SPM & Corrected (method n.r.) & n.r. & MNI & Tables 2, 3 \\
\hline
\end{tabular}




\begin{tabular}{|c|c|c|c|c|c|c|c|}
\hline 10 & Harada, K (2016) & $3 \mathrm{~T}$ & SPM & FWE & n.r. & $\mathrm{MNI}$ & Table 2 \\
\hline & Harada, K (2018) & $3 \mathrm{~T}$ & SPM & FWE & n.r. & MNI & Text \\
\hline 11 & Hou, Z (2016) & $3 \mathrm{~T}$ & SPM & AlphaSim $(\mathrm{k}=55, \mathrm{p}<0.001)$ & $\begin{array}{l}\text { GM volume, age, gender, } \\
\text { education level }\end{array}$ & $\mathrm{MNI}$ & Table 2 \\
\hline 12 & Huang, CM (2019) & $3 \mathrm{~T}$ & SPM & FWE $(p<0.001)$ & n.r. & MNI & Table 2 \\
\hline 13 & Hwang, JP (2010) & $2 \mathrm{~T}$ & SPM & Not Corrected $(\mathrm{p}<0.001)$ & $\begin{array}{l}\text { age, education level, duration } \\
\text { of illness }\end{array}$ & MNI & Table 2 \\
\hline 14 & Lee, TW (2013) & $3 \mathrm{~T}$ & AFNI & FWE $(k=20, p<0.005)$ & n.r. & Talairach & Table 4 \\
\hline 15 & Li, J (2020) & $3 \mathrm{~T}$ & SPM & AlphaSim $(\mathrm{p}<0.001)$ & $\begin{array}{l}\text { age, gender education level, } \\
\text { MMSE score, framewise } \\
\text { displacement }\end{array}$ & MNI & Table 2 \\
\hline 16 & Mah, L (2011) & $3 \mathrm{~T}$ & n.r. & n.r. & n.r. & Talairach & Text \\
\hline 17 & Oudega, ML (2014) & $1 \mathrm{~T}$ & SPM & Not Corrected $(\mathrm{k}=50, \mathrm{p}<0.001)$ & GM volume & $\mathrm{MNI}$ & Table 2 \\
\hline 18 & Respino, M (2019) & $3 \mathrm{~T}$ & SPM & FWE $(p<0.001)$ & $\begin{array}{l}\text { sex, education, mean } \\
\text { framewise displacement }\end{array}$ & $\mathrm{MNI}$ & Table 2 \\
\hline 19 & Ribeiz, SRI (2013) & $1.5 \mathrm{~T}$ & SPM & FWE & GM volume, education level & Talairach & Text \\
\hline 20 & Smith, GS (2009) & $1.5 \mathrm{~T}$ & SPM & Not Corrected $(\mathrm{k}=50, \mathrm{p}<001)$ & n.r. & $\mathrm{MNI}$ & Tables 1, 3b \\
\hline 21 & Takami, H (2007) & n.r. & SPM & Not Corrected $(\mathrm{p}<0.001)$ & n.r. & Talairach & Table 3 \\
\hline 22 & Wang, L (2008) & $4 \mathrm{~T}$ & custom script & Not Corrected $(\mathrm{k}=5, \mathrm{p}<001)$ & $\begin{array}{l}\text { age, education level, number } \\
\text { of episodes, duration of } \\
\text { disease }\end{array}$ & MNI & Table 2 \\
\hline 23 & Wong, NM (2016) & $3 \mathrm{~T}$ & FSL & FWE $(p<0.001)$ & n.r. & MNI & Text \\
\hline
\end{tabular}




$1.5 \mathrm{~T}$

SPM, AFNI AlphaSim $(k=270 \mathrm{~mm} 3, \mathrm{p}<0.005)$

n.r.

Talairach

Table 2

\begin{tabular}{|c|c|c|c|c|c|c|}
\hline Yuan, Y (2008b) & $1.5 \mathrm{~T}$ & SPM & Not Corrected $(\mathrm{k}=80 \mathrm{~mm} 3, \mathrm{p}<0.001)$ & n.r. & MNI & Table 2 \\
\hline Yue, Y (2015) & $3 \mathrm{~T}$ & SPM & Monte Carlo $(\mathrm{k}=2079 \mathrm{~mm} 3, \mathrm{p}<0.05)$ & n.r. & MNI & Table 2 \\
\hline
\end{tabular}

n.r. = not reported; n.a. = not applicable; $\mathrm{T}=$ Tesla; SPM = Statistical Parametric Mapping; FSL = FMRIB Software Library; AFNI = Analysis of Functional NeuroImages; FWE = family-wise error correction; FDR = false discovery rate; GM = grey matter; rCBF = relative cerebral blood flow; MMSE = mini-mental state examination; MNI = Montreal Neurological Institute;

${ }^{a}$ Publications with overlapping samples are grouped together 


\section{References}

Aizenstein, H. J., Baskys, A., Boldrini, M., Butters, M. A., Diniz, B. S., Jaiswal, M. K., .. Tene, O. (2016). Vascular depression consensus report-A critical update. Bmc Medicine, 14(1), 161. doi: 10.1186/s12916-016-0720-5

Albert, K., Gau, V., Taylor, W. D., \& Newhouse, P. A. (2017). Attention bias in older women with remitted depression is associated with enhanced amygdala activity and functional connectivity. Journal of Affective Disorders, 210, 49-56. doi: 10.1016/j.jad.2016.12.010

Alexopoulos, G. S. (2019). Mechanisms and treatment of late-life depression. Translational Psychiatry, 9(1), 188. doi: 10.1038/s41398-019-0514-6

Beekman, A. T. F., de Beurs, E., van Balkom, A. J. L. M., Deeg, D. J. H., van Dyck, R., \& van Tilburg, W. (2000). Anxiety and Depression in Later Life: Co-Occurrence and Communality of Risk Factors. American Journal of Psychiatry, 157(1), 89-95. doi: 10.1176/ajp.157.1.89

Beijers, L., Wardenaar, K. J., van Loo, H. M., \& Schoevers, R. A. (2019). Data-driven biological subtypes of depression: Systematic review of biological approaches to depression subtyping. Mol Psychiatry, 24(6), 888-900. doi: 10.1038/s41380-019-0385-5

Bobb, D. S., Adinoff, B., Laken, S. J., McClintock, S. M., Rubia, K., Huang, H. W., ... Andrew Kozel, F. (2012). Neural correlates of successful response inhibition in unmedicated patients with late-life depression. American Journal of Geriatric Psychiatry, 20(12), 1057-1069. doi: 10.1097/JGP.0b013e318235b728

Boccia, M., Acierno, M., \& Piccardi, L. (2015). Neuroanatomy of Alzheimer's Disease and Late-Life Depression: A Coordinate-Based Meta-Analysis of MRI Studies. Journal of Alzheimer's Disease : $J A D, 46(4)$, 963-970. doi: 10.3233/jad-142955

Botvinik-Nezer, R., Holzmeister, F., Camerer, C. F., Dreber, A., Huber, J., Johannesson, M., ... Schonberg, T. (2020). Variability in the analysis of a single neuroimaging dataset by many teams. Nature, 582(7810), 84-88. doi: 10.1038/s41586-020-2314-9

Bricenõ, E. M., Rapport, L. J., Kassel, M. T., Bieliauskas, L. A., Zubieta, J. K., Weisenbach, S. L., \& Langenecker, S. A. (2015). Age and gender modulate the neural circuitry supporting facial emotion processing in adults with major depressive disorder. American Journal of Geriatric Psychiatry, 23(3), 304-313. doi: 10.1016/j.jagp.2014.05.007

Button, K. S., Ioannidis, J. P., Mokrysz, C., Nosek, B. A., Flint, J., Robinson, E. S., \& Munafò, M. R. (2013). Power failure: Why small sample size undermines the reliability of neuroscience. Nature Reviews. Neuroscience, 14(5), 365-376. doi: 10.1038/nrn3475 
Byun, M. S., Choe, Y. M., Sohn, B. K., Yi, D., Han, J. Y., Park, J., .. Lee, D. Y. (2016). Association of cerebral amyloidosis, blood pressure, and neuronal injury with late-life onset depression. Frontiers in Aging Neuroscience, 8(OCT). doi: 10.3389/fnagi.2016.00236

Chen, J. D., Liu, F., Xun, G. L., Chen, H. F., Hu, M. R., Guo, X. F., ... Zhao, J. P. (2012). Early and late onset, first-episode, treatment-naive depression: Same clinical symptoms, different regional neural activities. Journal of Affective Disorders, 143(1-3), 56-63. doi: 10.1016/j.jad.2012.05.025

Colloby, S. J., Firbank, M. J., Vasudev, A., Parry, S. W., Thomas, A. J., \& O’Brien, J. T. (2011). Cortical thickness and VBM-DARTEL in late-life depression. Journal of Affective Disorders, 133(1-2), 158-164. doi: 10.1016/j.jad.2011.04.010

De Asis, J. M., Stern, E., Alexopoulos, G. S., Pan, H., Van Gorp, W., Blumberg, H., ... Silbersweig, D. A. (2001). Hippocampal and anterior cingulate activation deficits in patients with geriatric depression. American Journal of Psychiatry, 158(8), 1321-1323. doi: 10.1176/appi.ajp.158.8.1321

Delaloye, C., Moy, G., de Bilbao, F., Baudois, S., Weber, K., Hofer, F., ... Gold, G. (2010). Neuroanatomical and neuropsychological features of elderly euthymic depressed patients with early- and late-onset. Journal of the Neurological Sciences, 299(1-2), 19-23. doi: 10.1016/j.jns.2010.08.046

Delaveau, P., Jabourian, M., Lemogne, C., Guionnet, S., Bergouignan, L., \& Fossati, P. (2011). Brain effects of antidepressants in major depression: A meta-analysis of emotional processing studies. Journal of Affective Disorders, 130(1-2), 66-74. doi: 10.1016/j.jad.2010.09.032

Diniz, B. S., Butters, M. A., Albert, S. M., Dew, M. A., \& Reynolds, C. F. (2013). Late-life depression and risk of vascular dementia and Alzheimer's disease: Systematic review and meta-analysis of community-based cohort studies. The British Journal of Psychiatry: The Journal of Mental Science, 202(5), 329-335. doi: 10.1192/bjp.bp.112.118307

Dombrovski, A. Y., Szanto, K., Clark, L., Reynolds, I. C. F., \& Siegle, G. J. (2013). Reward signals, attempted suicide, and impulsivity in late-life depression. Jama Psychiatry, 70(10), 1020-1030. doi: $10.1001 /$ jamapsychiatry.2013.75

Drysdale, A. T., Grosenick, L., Downar, J., Dunlop, K., Mansouri, F., Meng, Y., ... Liston, C. (2017). Resting-state connectivity biomarkers define neurophysiological subtypes of depression. Nature Medicine, 23(1), 28-38. doi: 10.1038/nm.4246

Du, M., Liu, J., Chen, Z., Huang, X., Li, J., Kuang, W., ... Gong, Q. (2014). Brain grey matter volume alterations in late-life depression. Journal of Psychiatry and Neuroscience, 39(6), 397-406. doi: 10.1503/jpn.130275

Dumas, J. A., \& Newhouse, P. A. (2015). Impaired working memory in geriatric depression: An 
fMRI study. American Journal of Geriatric Psychiatry, 23(4), 433-436. doi: 10.1016/j.jagp.2014.09.011

Eickhoff, S. B., Bzdok, D., Laird, A. R., Kurth, F., \& Fox, P. T. (2012). Activation likelihood estimation meta-analysis revisited. NeuroImage, 59(3), 2349-2361. doi: 10.1016/j.neuroimage.2011.09.017

Eickhoff, S. B., Laird, A. R., Fox, P. M., Lancaster, J. L., \& Fox, P. T. (2017). Implementation errors in the GingerALE Software: Description and recommendations. Human Brain Mapping, 38(1), 7-11. doi: 10.1002/hbm.23342

Eickhoff, S. B., Nichols, T. E., Laird, A. R., Hoffstaedter, F., Amunts, K., Fox, P. T., ... Eickhoff, C. R. (2016). Behavior, sensitivity, and power of activation likelihood estimation characterized by massive empirical simulation. NeuroImage, 137, 70-85. doi: 10.1016/j.neuroimage.2016.04.072

Fang, J., Mao, N., Jiang, X., Li, X., Wang, B., \& Wang, Q. (2015). Functional and Anatomical Brain Abnormalities and Effects of Antidepressant in Major Depressive Disorder: Combined Application of Voxel-Based Morphometry and Amplitude of Frequency Fluctuation in Resting State. Journal of Computer Assisted Tomography, 39(5), 766-773. doi: $10.1097 /$ rct.0000000000000264

Fiske, A., Wetherell, J. L., \& Gatz, M. (2009). Depression in older adults. Annu Rev Clin Psychol, 5, 363-389. doi: 10.1146/annurev.clinpsy.032408.153621

Giehl, K., Tahmasian, M., Eickhoff, S. B., \& van Eimeren, T. (2019). Imaging executive functions in Parkinson's disease: An activation likelihood estimation meta-analysis. Parkinsonism \& Related Disorders, 63, 137-142. doi: 10.1016/j.parkreldis.2019.02.015

Glatard, T., Lewis, L. B., Ferreira da Silva, R., Adalat, R., Beck, N., Lepage, C., ... Evans, A. C. (2015). Reproducibility of neuroimaging analyses across operating systems. Frontiers in Neuroinformatics, 9. doi: 10.3389/fninf.2015.00012

Global Burden of Disease Collaborative Network. (2018). Global Burden of Disease Study 2017 (GBD 2017) Results. Seattle, United States: Institute for Health Metrics and Evaluation (IHME). Available from http://ghdx.healthdata.org/gbd-results-tool.

Goldberg, D. (2011). The heterogeneity of “major depression.” World Psychiatry, 10(3), 226-228. doi: 10.1002/j.2051-5545.2011.tb00061.x

Gorgolewski, K. J., Varoquaux, G., Rivera, G., Schwarz, Y., Ghosh, S. S., Maumet, C., ... Margulies, D. S. (2015). NeuroVault.org: A web-based repository for collecting and sharing unthresholded statistical maps of the human brain. Frontiers in Neuroinformatics, 9. doi: 10.3389/fninf.2015.00008 
Gray, J. P., Müller, V. I., Eickhoff, S. B., \& Fox, P. T. (2020). Multimodal Abnormalities of Brain Structure and Function in Major Depressive Disorder: A Meta-Analysis of Neuroimaging Studies. The American Journal of Psychiatry, 177(5), 422-434. doi: 10.1176/appi.ajp.2019.19050560

Gudayol-Ferre, E., Pero-Cebollero, M., Gonzalez-Garrido, A. A., \& Guardia-Olmos, J. (2015). Changes in brain connectivity related to the treatment of depression measured through fMRI: a systematic review. Frontiers in Human Neuroscience, 9. (WOS:000366493400001). doi: 10.3389/fnhum.2015.00582

Guo, W. B., Liu, F., Xun, G. L., Hu, M. R., Guo, X. F., Xiao, C. Q., ... Zhao, J. P. (2013). Reversal alterations of amplitude of low-frequency fluctuations in early and late onset, first-episode, drug-naive depression. Progress in Neuro-Psychopharmacology and Biological Psychiatry, 40(1), 153 159. doi: 10.1016/j.pnpbp.2012.08.014

Harada, K., Ikuta, T., Nakashima, M., Watanuki, T., Hirotsu, M., Matsubara, T., ... Matsuo, K. (2018). Altered connectivity of the anterior cingulate and the posterior superior temporal gyrus in a longitudinal study of later-life depression. Frontiers in Aging Neuroscience, 10(FEB). doi: 10.3389/fnagi.2018.00031

Harada, K., Matsuo, K., Nakashima, M., Hobara, T., Higuchi, N., Higuchi, F., ... Watanabe, Y. (2016). Disrupted orbitomedial prefrontal limbic network in individuals with later-life depression. Journal of Affective Disorders, 204, 112-119. doi: 10.1016/j.jad.2016.06.031

Hegeman, J. M., Kok, R. M., van der Mast, R. C., \& Giltay, E. J. (2012). Phenomenology of depression in older compared with younger adults: Meta-analysis. Br J Psychiatry, 200(4), 275 281. doi: 10.1192/bjp.bp.111.095950

Hou, Z., Sui, Y., Song, X., \& Yuan, Y. (2016). Disrupted interhemispheric synchrony in default mode network underlying the impairment of cognitive flexibility in late-onset depression. Frontiers in Aging Neuroscience, 8(SEP). doi: 10.3389/fnagi.2016.00230

Huang, C. M., Fan, Y. T., Lee, S. H., Liu, H. L., Chen, Y. L., Lin, C., \& Lee, T. M. C. (2019). Cognitive reserve-mediated neural modulation of emotional control and regulation in people with late-life depression. Social Cognitive and Affective Neuroscience, 14(8), 849-860. doi: $10.1093 /$ scan/nsz054

Huang, X., Rootes-Murdy, K., Bastidas, D. M., Nee, D. E., \& Franklin, J. C. (2020). Brain Differences Associated with Self-Injurious Thoughts and Behaviors: A Meta-Analysis of Neuroimaging Studies. Scientific Reports, 10(1), 2404. doi: 10.1038/s41598-020-59490-6

Hwang, J. P., Lee, T. W., Tsai, S. J., Chen, T. J., Yang, C. H., Lirng, J. F., \& Tsai, C. F. (2010). Cortical and subcortical abnormalities in late-onset depression with history of suicide 
attempts investigated with MRI and voxel-based morphometry. Journal of Geriatric Psychiatry and Neurology, 23(3), 171-184. doi: 10.1177/0891988710363713

Ioannidis, J. P. A. (2005). Why Most Published Research Findings Are False. PLOS Medicine, 2(8), e124. doi: 10.1371/journal.pmed.0020124

Karakus, M. C., \& Patton, L. C. (2011). Depression and the onset of chronic illness in older adults: A 12-year prospective study. The Journal of Behavioral Health Services \& Research, 38(3), 373-382. doi: 10.1007/s11414-011-9234-2

Kharabian Masouleh, S., Eickhoff, S. B., Hoffstaedter, F., Genon, S., \& Alzheimer's Disease Neuroimaging Initiative. (2019). Empirical examination of the replicability of associations between brain structure and psychological variables. ELife, 8, e43464. doi: 10.7554/eLife.43464

Koenig, A. M., Bhalla, R. K., \& Butters, M. A. (2014). Cognitive functioning and late-life depression. Journal of the International Neuropsychological Society, 20(5), 461-467. doi: 10.1017/S1355617714000198

Lancaster, J. L., Tordesillas-Gutiérrez, D., Martinez, M., Salinas, F., Evans, A., Zilles, K., ... Fox, P. T. (2007). Bias between MNI and Talairach coordinates analyzed using the ICBM-152 brain template. Human Brain Mapping, 28(11), 1194-1205. doi: 10.1002/hbm.20345

Lavretsky, H., Kurbanyan, K., Ballmaier, M., Mintz, J., Toga, A., \& Kumar, A. (2004). Sex differences in brain structure in geriatric depression. The American Journal of Geriatric Psychiatry: Official Journal of the American Association for Geriatric Psychiatry, 12(6), 653-657. doi: 10.1176/appi.ajgp.12.6.653

Lee, T. W., Liu, H. L., Wai, Y. Y., Ko, H. J., \& Lee, S. H. (2013). Abnormal neural activity in partially remitted late-onset depression: An fMRI study of one-back working memory task. Psychiatry Research - Neuroimaging, 213(2), 133-141. doi: 10.1016/j.pscychresns.2012.04.010

Li, J., Gong, H., Xu, H., Ding, Q., He, N., Huang, Y., ... Zhan, S. (2020). Abnormal Voxel-Wise Degree Centrality in Patients With Late-Life Depression: A Resting-State Functional Magnetic Resonance Imaging Study. Frontiers in Psychiatry, 10. doi: 10.3389/fpsyt.2019.01024

Liu, F., Hu, M., Wang, S., Guo, W., Zhao, J., Li, J., ... Chen, H. (2012). Abnormal regional spontaneous neural activity in first-episode, treatment-naive patients with late-life depression: A resting-state fMRI study. Progress in Neuro-Psychopharmacology and Biological Psychiatry, 39(2), 326-331. doi: 10.1016/j.pnpbp.2012.07.004

Lugtenburg, A., Zuidersma, M., Wardenaar, K. J., Aprahamian, I., Rhebergen, D., Schoevers, R. A., \& Oude Voshaar, R. C. (2020). Late-life related subtypes of depression-A data-driven approach on cognitive domains and physical frailty. The Journals of Gerontology. Series A, 
Biological Sciences and Medical Sciences. doi: 10.1093/gerona/glaa110

Lynch, C. J., Gunning, F. M., \& Liston, C. (2020). Causes and Consequences of Diagnostic Heterogeneity in Depression: Paths to Discovering Novel Biological Depression Subtypes. Biol Psychiatry. (32171465). doi: 10.1016/j.biopsych.2020.01.012

Mah, L., Williams, L. J., Leung, R., Freel, S., \& Pollock, B. G. (2011). Neural substrates of emotional processing in late-life depression. Biological Psychiatry, 69(9), 139S. doi: 10.1016/j.biopsych.2011.03.031

Mahgoub, N., \& Alexopoulos, G. S. (2016). The Amyloid Hypothesis: Is There a Role for Antiamyloid Treatment in Late-Life Depression? The American Journal of Geriatric Psychiatry: Official Journal of the American Association for Geriatric Psychiatry, 24(3), 239-247. doi: 10.1016/j.jagp.2015.12.003

Manning, K., Wang, L., \& Steffens, D. (2019). Recent advances in the use of imaging in psychiatry: Functional magnetic resonance imaging of large-scale brain networks in late-life depression. F1000Res, 8. doi: 10.12688/f1000research.17399.1

Marano, C. M., Workman, C. I., Lyman, C. H., Munro, C. A., Kraut, M. A., \& Smith, G. S. (2015). Structural imaging in late-life depression: Association with mood and cognitive responses to antidepressant treatment. American Journal of Geriatric Psychiatry, 23(1), 4-12. doi: 10.1016/j.jagp.2013.10.001

McKinnon, M. C., Yucel, K., Nazarov, A., \& MacQueen, G. M. (2009). A meta-analysis examining clinical predictors of hippocampal volume in patients with major depressive disorder. Journal of Psychiatry \& Neuroscience: JPN, 34(1), 41-54.

Moher, D., Liberati, A., Tetzlaff, J., Altman, D. G., \& Group, P. (2009). Preferred reporting items for systematic reviews and meta-analyses: The PRISMA statement. PLoS Med, 6(7), e1000097. doi: 10.1371/journal.pmed.1000097

Müller, V. I., Cieslik, E. C., Laird, A. R., Fox, P. T., Radua, J., Mataix-Cols, D., ... Eickhoff, S. B. (2018). Ten simple rules for neuroimaging meta-analysis. Neuroscience \& Biobehavioral Reviews, 84,151-161. doi: 10.1016/j.neubiorev.2017.11.012

Muller, V. I., Cieslik, E. C., Serbanescu, I., Laird, A. R., Fox, P. T., \& Eickhoff, S. B. (2017). Altered Brain Activity in Unipolar Depression Revisited: Meta-analyses of Neuroimaging Studies. JAMA Psychiatry, 74(1), 47-55. (27829086). doi: 10.1001/jamapsychiatry.2016.2783

Nelson, J. C., Clary, C. M., Leon, A. C., \& Schneider, L. S. (2005). Symptoms of late-life depression: Frequency and change during treatment. The American Journal of Geriatric Psychiatry: Official Journal of the American Association for Geriatric Psychiatry, 13(6), 520-526. doi: 10.1176/appi.ajgp.13.6.520 
Nickl-Jockschat, T., Janouschek, H., Eickhoff, S. B., \& Eickhoff, C. R. (2015). Lack of MetaAnalytic Evidence for an Impact of COMT Val158Met Genotype on Brain Activation During Working Memory Tasks. Biological Psychiatry, 78(11), e43-e46. doi: 10.1016/j.biopsych.2015.02.030

Oudega, M. L., van Exel, E., Stek, M. L., Wattjes, M. P., van der Flier, W. M., Comijs, H. C., ... van den Heuvel, O. A. (2014). The structure of the geriatric depressed brain and response to electroconvulsive therapy. Psychiatry Research - Neuroimaging, 222(1-2), 1-9. doi: 10.1016/j.pscychresns.2014.03.002

Patel, M. J., Boada, F. E., Price, J. C., Sheu, L. K., Tudorascu, D. L., Reynolds, I. C. F., \& Aizenstein, H. J. (2012). Association of small vessel ischemic white matter changes with BOLD fMRI imaging in the elderly. Psychiatry Research - Neuroimaging, 204(2-3), 117-122. doi: 10.1016/j.pscychresns.2012.09.006

Poldrack, R. A., Baker, C. I., Durnez, J., Gorgolewski, K. J., Matthews, P. M., Munafò, M. R., ... Yarkoni, T. (2017). Scanning the horizon: Towards transparent and reproducible neuroimaging research. Nature Reviews. Neuroscience, 18(2), 115-126. doi: $10.1038 / \mathrm{nrn} .2016 .167$

Rao, J. A., Kassel, M. T., Weldon, A. L., Avery, E. T., Briceno, E. M., Mann, M., ... Weisenbach, S. L. (2015). The double burden of age and major depressive disorder on the cognitive control network. Psychology and Aging, 30(2), 475-485. doi: 10.1037/pag0000027

Respino, M., Hoptman, M. J., Victoria, L. W., Alexopoulos, G. S., Solomonov, N., Stein, A. T., ... Gunning, F. M. (2019). Cognitive Control Network Homogeneity and Executive Functions in Late-Life Depression. Biological Psychiatry: Cognitive Neuroscience and Neuroimaging. doi: 10.1016/j.bpsc.2019.10.013

Ribeiz, S. R. I., Duran, F., Oliveira, M. C., Bezerra, D., Castro, C. C., Steffens, D. C., ... Bottino, C. M. C. (2013). Structural Brain Changes as Biomarkers and Outcome Predictors in Patients with Late-Life Depression: A CrossSectional and Prospective Study. Plos One, 8(11). doi: 10.1371/journal.pone.0080049

Ritchie, S. J., Cox, S. R., Shen, X., Lombardo, M. V., Reus, L. M., Alloza, C., ... Deary, I. J. (2018). Sex Differences in the Adult Human Brain: Evidence from 5216 UK Biobank Participants. Cerebral Cortex (New York, N.Y.: 1991), 28(8), 2959-2975. doi: 10.1093/cercor/bhy109

Rubinov, M., \& Sporns, O. (2010). Complex network measures of brain connectivity: Uses and interpretations. NeuroImage, 52(3), 1059-1069. doi: 10.1016/j.neuroimage.2009.10.003

Salimi-Khorshidi, G., Smith, S. M., Keltner, J. R., Wager, T. D., \& Nichols, T. E. (2009). Metaanalysis of neuroimaging data: A comparison of image-based and coordinate-based pooling 
of studies. NeuroImage, 45(3), 810-823. doi: 10.1016/j.neuroimage.2008.12.039

Samea, F., Soluki, S., Nejati, V., Zarei, M., Cortese, S., Eickhoff, S. B., ... Eickhoff, C. R. (2019). Brain alterations in children/adolescents with ADHD revisited: A neuroimaging metaanalysis of 96 structural and functional studies. Neuroscience and Biobehavioral Reviews, 100, 1-8. doi: 10.1016/j.neubiorev.2019.02.011

Sexton, C. E., Allan, C. L., Le Masurier, M., McDermott, L. M., Kalu, U. G., Herrmann, L. L., ... Ebmeier, K. P. (2012). Magnetic resonance imaging in late-life depression: Multimodal examination of network disruption. Archives of General Psychiatry, 69(7), 680-689. doi: 10.1001/archgenpsychiatry.2011.1862

Sheng, L., Zhao, P., Ma, H., Yuan, C., Zhong, J., Dai, Z., \& Pan, P. (2020). A lack of consistent brain grey matter alterations in migraine. Brain, 143(6), e45-e45. doi: 10.1093/brain/awaa123

Sin, E. L. L., Liu, H. L., Lee, S. H., Huang, C. M., Wai, Y. Y., Chen, Y. L., ... Lee, T. M. C. (2018). The relationships between brain structural changes and perceived loneliness in older adults suffering from late-life depression. International Journal of Geriatric Psychiatry, 33(4), 606-612. doi: $10.1002 /$ gps.4831

Smith, G. S., Kramer, E., Ma, Y., Kingsley, P., Dhawan, V., Chaly, T., \& Eidelberg, D. (2009). The functional neuroanatomy of geriatric depression. International Journal of Geriatric Psychiatry, 24(8), 798-808. doi: 10.1002/gps.2185

Smith, G. S., Reynolds, I. C. F., Houck, P. R., Dew, M. A., Ginsberg, J., Ma, Y., .. Pollock, B. G. (2009). Cerebral glucose metabolic response to combined total sleep deprivation and antidepressant treatment in geriatric depression: A randomized, placebo-controlled study. Psychiatry Research - Neuroimaging, 171(1), 1-9. doi: 10.1016/j.pscychresns.2008.05.001

Szanto, K., Dombrovski, A. Y., Sahakian, B. J., Mulsant, B. H., Houck, P. R., Reynolds, C. F., \& Clark, L. (2012). Social emotion recognition, social functioning, and attempted suicide in late-life depression. The American Journal of Geriatric Psychiatry: Official Journal of the American Association for Geriatric Psychiatry, 20(3), 257-265. doi: 10.1097/JGP.0b013e31820eea0c

Tadayonnejad, R., \& Ajilore, O. (2014). Brain network dysfunction in late-life depression: A literature review. Journal of Geriatric Psychiatry and Neurology, 27(1), 5-12. doi: $10.1177 / 0891988713516539$

Tahmasian, M., Noori, K., Samea, F., Zarei, M., Spiegelhalder, K., Eickhoff, S. B., ... Eickhoff, C. R. (2018). A lack of consistent brain alterations in insomnia disorder: An activation likelihood estimation meta-analysis. Sleep Medicine Reviews, 42, 111-118. doi: 10.1016/j.smrv.2018.07.004

Tahmasian, M., Sepehry, A. A., Samea, F., Khodadadifar, T., Soltaninejad, Z., Javaheripour, N., ... Eickhoff, C. R. (2019). Practical recommendations to conduct a neuroimaging meta-analysis 
for neuropsychiatric disorders. Human Brain Mapping, 40(17), 5142-5154. doi: 10.1002/hbm.24746

Tahmasian, M., Zarei, M., Noori, K., Khazaie, H., Samea, F., Spiegelhalder, K., ... Eickhoff, C. R. (2018). Reply to Hua Liu, HaiCun Shi and PingLei Pan: Coordinate based meta-analyses in a medium sized literature: Considerations, limitations and road ahead. Sleep Medicine Reviews, 42, 236-238. doi: 10.1016/j.smrv.2018.08.004

Takami, H., Okamoto, Y., Yamashita, H., Okada, G., \& Yamawaki, S. (2007). Attenuated anterior cingulate activation during a verbal fluency task in elderly patients with a history of Multipleepisode depression. American Journal of Geriatric Psychiatry, 15(7), 594-603. doi: 10.1097/01.JGP.0b013e31802ea919

Tedeschini, E., Levkovitz, Y., Iovieno, N., Ameral, V. E., Nelson, J. C., \& Papakostas, G. I. (2011). Efficacy of antidepressants for late-life depression: A meta-analysis and meta-regression of placebo-controlled randomized trials. The Journal of Clinical Psychiatry, 72(12), 1660-8. doi: 10.4088/JCP.10r06531

Tittmann, M., Gunther, T., Sacher, J., Himmerich, H., Villringer, A., Hegerl, U., \& Schonknecht, P. (2014). Structural Brain Changes in Early-Onset and Late-Onset Depression: An Update of Volumetric MRI Findings. International Journal of Imaging Systems and Technology, 24(2), 149-160. doi: 10.1002/ima.22089

Turkeltaub, P. E., Eickhoff, S. B., Laird, A. R., Fox, M., Wiener, M., \& Fox, P. (2012). Minimizing within-experiment and within-group effects in Activation Likelihood Estimation metaanalyses. Human Brain Mapping, 33(1), 1-13. doi: 10.1002/hbm.21186

Vaishnavi, S., \& Taylor, W. D. (2006). Neuroimaging in late-life depression. International Review of Psychiatry, 18(5), 443-451. doi: 10.1080/09540260600935454

van Agtmaal, M. J. M., Houben, A. J. H. M., Pouwer, F., Stehouwer, C. D. A., \& Schram, M. T. (2017). Association of Microvascular Dysfunction With Late-Life Depression: A Systematic Review and Meta-analysis. JAMA Psychiatry, 74(7), 729-739. doi: 10.1001/jamapsychiatry.2017.0984

Vanyukov, P. M., Szanto, K., Siegle, G. J., Hallquist, M. N., Reynolds, C. F., Aizenstein, H. J., \& Dombrovski, A. Y. (2015). Impulsive traits and unplanned suicide attempts predict exaggerated prefrontal response to angry faces in the elderly. American Journal of Geriatric Psychiatry, 23(8), 829-839. doi: 10.1016/j.jagp.2014.10.004

Wang, L., Krishnan, K. R., Steffens, D. C., Potter, G. G., Dolcos, F., \& McCarthy, G. (2008). Depressive state- and disease-related alterations in neural responses to affective and executive challenges in geriatric depression. American Journal of Psychiatry, 165(7), 863-871. 
doi: 10.1176/appi.ajp.2008.07101590

Weber, K., Giannakopoulos, P., Delaloye, C., de Bilbao, F., Moy, G., Ebbing, K., .. Canuto, A. (2012). Personality traits, cognition and volumetric MRI changes in elderly patients with early-onset depression: A 2-year follow-up study. Psychiatry Research, 198(1), 47-52. doi: 10.1016/j.psychres.2011.11.017

Weber, K., Giannakopoulos, P., Delaloye, C., de Bilbao, F., Moy, G., Moussa, A., ... Canuto, A. (2010). Volumetric MRI changes, cognition and personality traits in old age depression. Journal of Affective Disorders, 124(3), 275-282. doi: 10.1016/j.jad.2009.11.016

Wei, J., Hou, R., Zhang, X., Xu, H., Xie, L., Chandrasekar, E. K., ... Goodman, M. (2019). The association of late-life depression with all-cause and cardiovascular mortality among community-dwelling older adults: Systematic review and meta-analysis. Br J Psychiatry, 215(2), 449-455. doi: 10.1192/bjp.2019.74

Weisenbach, S. L., Kassel, M. T., Rao, J., Weldon, A. L., Avery, E. T., Briceno, E. M., ... Langenecker, S. A. (2014). Differential prefrontal and subcortical circuitry engagement during encoding of semantically related words in patients with late-life depression. International Journal of Geriatric Psychiatry, 29(11), 1104-1115. doi: 10.1002/gps.4165

Wen, M. C., Steffens, D. C., Chen, M. K., \& Zainal, N. H. (2014). Diffusion tensor imaging studies in late-life depression: Systematic review and meta-analysis. International Journal of Geriatric Psychiatry, 29(12), 1173-1184. doi: 10.1002/gps.4129

Wong, N. M., Liu, H. L., Lin, C., Huang, C. M., Wai, Y. Y., Lee, S. H., \& Lee, T. M. (2016). Loneliness in late-life depression: Structural and functional connectivity during affective processing. Psychological Medicine, 46(12), 2485-2499. doi: 10.1017/S0033291716001033

Xie, C., Li, W., Chen, G., Douglas Ward, B., Franczak, M. B., Jones, J. L., ... Goveas, J. S. (2012). The co-existence of geriatric depression and amnestic mild cognitive impairment detrimentally affect gray matter volumes: Voxel-based morphometry study. Behavioural Brain Research, 235(2), 244-250. doi: 10.1016/j.bbr.2012.08.007

Yuan, Y., Zhang, Z., Bai, F., Yu, H., Shi, Y., Qian, Y., ... Liu, Z. (2008). Abnormal neural activity in the patients with remitted geriatric depression: A resting-state functional magnetic resonance imaging study. Journal of Affective Disorders, 111(2-3), 145-152. doi: 10.1016/j.jad.2008.02.016

Yuan, Y., Zhu, W., Zhang, Z., Bai, F., Yu, H., Shi, Y., ... Liu, Z. (2008). Regional Gray Matter Changes Are Associated with Cognitive Deficits in Remitted Geriatric Depression: An Optimized Voxel-Based Morphometry Study. Biological Psychiatry, 64(6), 541-544. doi: 10.1016/j.biopsych.2008.04.032

Yue, Y., Jia, X., Hou, Z., Zang, Y., \& Yuan, Y. (2015). Frequency-dependent amplitude alterations 
of resting-state spontaneous fluctuations in late-onset depression. Biomed Research International, 2015. doi: 10.1155/2015/505479

Zang, Y., Jiang, T., Lu, Y., He, Y., \& Tian, L. (2004). Regional homogeneity approach to fMRI data analysis. Neuroimage, 22(1), 394-400.

Zivin, K., Wharton, T., \& Rostant, O. (2013). The economic, public health, and caregiver burden of late-life depression. Psychiatr Clin North Am, 36(4), 631-649. doi: 10.1016/j.psc.2013.08.008

Zou, Q.-H., Zhu, C.-Z., Yang, Y., Zuo, X.-N., Long, X.-Y., Cao, Q.-J., ... Zang, Y.-F. (2008). An improved approach to detection of amplitude of low-frequency fluctuation (ALFF) for resting-state fMRI: Fractional ALFF. Journal of Neuroscience Methods, 172(1), 137-141. 